University for Business and Technology in Kosovo

UBT Knowledge Center

UBT International Conference

2013 UBT International Conference

Nov 2nd, 9:20 AM - 9:30 AM

\title{
The Effects of Self-Esteem, Virtuousness and Work Values on the Ethical Behaviors: An Empirical Study in the Hotel Industry
}

\author{
Pelin Kanten \\ Mehmet Akif Ersoy University, pelinkanten@mehmetakif.edu.tr \\ Murat Yesiltas \\ Mehmet Akif Ersoy University, yesiltas.murat@mehmetakif.edu.tr \\ Selahattin Kanten \\ Mehmet Akif Ersoy University, selahattinkanten@mehmetakif.edu.tr
}

Follow this and additional works at: https://knowledgecenter.ubt-uni.net/conference

Part of the Business Commons

\footnotetext{
Recommended Citation

Kanten, Pelin; Yesiltas, Murat; and Kanten, Selahattin, "The Effects of Self-Esteem, Virtuousness and Work Values on the Ethical Behaviors: An Empirical Study in the Hotel Industry" (2013). UBT International Conference. 34.

https://knowledgecenter.ubt-uni.net/conference/2013/all-events/34

This Event is brought to you for free and open access by the Publication and Journals at UBT Knowledge Center. It has been accepted for inclusion in UBT International Conference by an authorized administrator of UBT Knowledge Center. For more information, please contact knowledge.center@ubt-uni.net.
} 


\title{
The Effects of Self-Esteem, Virtuousness and Work Values on the Ethical Behaviors: An Empirical Study in the Hotel Industry
}

\author{
Pelin KANTEN ${ }^{1}$, Murat YESILTAS ${ }^{2}$, Selahattin KANTEN $^{3}$ \\ ${ }^{123}$ Mehmet Akif Ersoy University, School of Tourism and Hotel Management, Burdur, Turkey, \\ pelinkanten@mehmetakif.edu.tr ${ }^{1}$, yesiltas.murat@mehmetakif.edu.tr ${ }^{2}$. \\ selahattinkanten@mehmetakif.edu.tr ${ }^{3}$
}

\begin{abstract}
This study investigates the impact of self-esteem, virtuousness and work values on ethical behaviors. In literature, studies suggest that individual and organizational factors as an important determinant or precurs or of ethical behaviors. However, there has been relatively little substantive research focusing on these issues. In this respect, significant findings have been collected as a result of a research conducted on 174 employees of ten hotel enterprises in Turkey. Based on the findings, significant relationships have been observed among self-esteem, virtuousness, work values and ethical behaviors. Accordingly, one of the dimensions of virtuousness and self-esteem affect ethical behaviors positively. Moreover, dimensions of work values such as influence and advancement, working relationships and financial \& working conditions are found out to have effect on ethical behaviors.
\end{abstract}

Keywor ds: Ethical behaviors, work values, self-esteem, virtuousness

\section{Introduction}

Ethics has become one of the most significant issues facing today's corporate world because of the Enron, WorldCom, Arthur Andersen and Tyco International scandals. Due to concerns about scandals and unethicalbehavior that have shaken the business world fromtime to time, interest in business ethics has grown exponentially in recent times for both managers and researchers. In accordance with these ongoing interests, scholars and practitioners are wondering what has to be done to assure ethical behaviors and attitudes in the business environment (Aydemir and Egilmez, 2010: 72; Sánchez and Medina, 2012: 2). Therefore, it is critical for organizations to establish an ethical culture in which employees are encouraged to behave in an ethical manner (Baker, Hunt and Andrews, 2006: 849). Because ethical manner or ethical behavior is one of the valuable intangible assets for org anizations competing in today's business world, so it is important to design an ethical culture that is perceived by employees and guiding them to act on ethical aspirations (Azmi, 2006: 2-3). Based on the importance of ethical behaviors in organizations, previous researches have investigated the role of a number of influences on ethical behavior. These influences have been classified as either individual or situational. Individual characteristics include values, demographic characteristics such as sex, and age, and education, personality traits like locus of control, self-esteem, and virtuousness. However, situational characteristics include reward systems, rules, social learning, loyalty, job security, ethical culture, workplace factors and work values. In literature, researchers have found links among ethical behaviors and some individual and organizational factors. Furthermore, all researchers agree that it is important for management to understand what influences the behaviors of individuals and how they derive ethical culture (Baker, Hunt and Andrews, 2006: 849; McDevitt, Giapponi and Tromley, 2007: 219; Rezaee, 2008: 69, Zaal, 2011: 51; Trevino and Nelson, 2011: 76). Self-esteem and virtuousness as an individual; work values as an organizational factors that being able to affect ethical behaviors. Self-esteem is a personal evaluation reflecting what people think of themselves as individuals. In other words, it refers a self-evaluation and descriptive conceptualization that individuals make and maintain with regard to themselves (Pierce and Gardner, 2004: 592). Virtuousness is what individuals aspire to be when they are at their best and it refers to qualities that allow people to excel (Caza, Barker and Cameron, 2004: 173). Work values defined as the states people desire and feel they ought to be able to realize through 
working. However, work values mediate an individual's preferences, tendencies and work goals (Wang, Chen, Hyde and Hsieh, 2010: 873). So, there are a few researches that show the relationship between individual and organizational factors and ethical behaviors. For instance, most studies focus on the relationship of ethical behaviors with some of the variables such as locus of control, organizational culture, ethical values, organizational justice, organizational commitment, etc. However, there are not any research existing literature investigating the impact of self-esteem, virtuousness and work values on ethical behaviors. Due to limited studies on the effects of these variables on the ethical behaviors, this study attempts to add to the area of organizational behavior research. In this context, the purpose of this study is to investigate the effect of the self-esteem, virtuousness and work values upon the employees' ethical behaviors.

\section{Literature Review}

Ethical behavior at the organizational and individual level has been of considerable interest particularly in hotel industry. Hotel industry comprises frontline employees who have to interact most frequently with customers, so employees' actions could potentially have a significant impact on the organizational success. For this reason, hotel establishments emphasizes that the importance of promoting and managing ethical behaviors (McCain, Tsai and Bellino, 2010: 993; Selvarajan and Sardessai, 2010:1). Managing ethical behavior is one of the most pervasive and complex problems facing organizations. Because, ethical behavior of employees in working area, lead organizations to achieve success and provide their abilities efficiently. Concordantly, it can be said that ethical behavior of employees is important by reason of positive influence on organizational performance (Gangwani, 2012: 44). In process of time, when ethical behaviors become a critical role in organizational processes clearer, researchers are directed to identify the factors that influence these behaviors. These factors generally are regarded as based organizations and individuals, and provide employees demonstrate ethical behavior and facilitate the demonstration of ethical behavior. Therefore, in this study we are discussed self-esteem and virtuousness as an individual perspective, on the other hand, work values as an organizational sense. In this context, primarily we will explain concepts of self-esteem, virtuousness, work values and ethical behaviors. Following them we will discuss the relationships between these concepts.

\subsection{Self-Esteem and Virtuousness}

Employees' individual characteristics and factors are believed to contribute to ethical behavior. These characteristics refer to an individual's knowledge, values, attitudes, intentions, moral character, locus of control, self-esteem etc. (McCain, Tsai and Bellino, 2010: 995). Self-esteem and virtuousness constitute the most important factors affecting the ethical behaviors in organizations. Rosenberg (1965) defined self-esteem as individuals overall evaluation about their competencies (Treadway, 2012: 542). Self-esteem is an "evaluation" which the individual makes and customarily maintains with regard to the self. However, self-esteem indicates the extent to which the individual believes the self to be capable, significant, successful and worthy (Ma, 2008: 1). Wells and Marwell attempted to organize definitions of "self-esteem" on the basis of two psychological processes as an evaluation and affect. Evaluation emphasizes the role of cognition and affect prioritizes the role of feelings. As a result of this approach, self-esteem can be defined in different ways. According to the first and most basic definition self-esteem as a certain attitude. To the extent of other point of view, self-esteem characterizes discrepancy between the self that one wishes to be. In conclusion, self-esteem is understood as a function or component of personality (Mruk, 2006: 10-11).

In literature, there is an ongoing debate about conceptualization of self-esteem and its effect. Researchers have been suggested that self-esteem has a significant impact on important life domains, including work. With regard to the work domain, previous research indicates that self-esteem is correlated with job satisfaction, job performance, career success, and employee motivation, and positive interpersonal relations, physical and mental health. However, psychologists believed that low selfesteem was an important cause of aggression and antisocial behaviors. Concordantly, self-esteem can be seen as a determinant factor that affects behaviors of employees and also contributing to quality of 
their work life (Baumeister, Campbell, Krueger and Vohs, 2003: 10-24; Mann, Hosman, Schaalma and Vries, 2004: 358; Pierce and Gardner, 2004: 591; Ferris et al., 2010: 561; Kuster, Orth and Meier, 2013: 1). Thus, it is possible to express that self-esteem is a basic human virtue or strength. In other words, self-esteem based on a sense of virtue or moral worth. Coopersmith (1967) who was one of the first researchers studying on self-esteem found that there are four resources of self-esteem. Power, significance, competence and virtue are the sources of self-esteem (Mruk, 2006: 20-256). Self-esteem can become contingent based on being attractive, being valued, demonstrating competence or demonstrating virtue. Therefore, virtue or virtuousness is one of the important determinants of selfesteem (Ferris et al., 2010: 568). Virtue or virtuousness is a state of human character that guides people to do "good". Virtuousness is an excellent combination of traits usually understood as dispositions of individuals, which is significant in the discovery of truth and in leading a good life (Hackett and Wang, 2012: 870-873). Generally, virtuousness defined as a qualitative characteristic which includes integrity, compassion, and courage. In other words, virtuousness refers to acting in a sincere way, not being vengeful, helping people and taking care of them, involving perseverance etc. (Rego, Cunha and Clegg, 2012: 7-8). However, virtuousness means living the good life and incorporating virtue in all aspects of oneself thinking, behaving, feeling, and being. Thus a person who described as a virtuous act kindly, emote kindness, and be kind in every dimension of his or her life (Barsky, 2010: 2). So, virtuousness seen as an important factor that provides benefit to individuals, other people, and general society. Because of its critical role, virtue has become as a remarkable topic of study in both psychology and positive organizational scholarship. Researches in this area has examined virtuousness in various organizational contexts and related it to several outcomes at an individual and organizational level. Particularly, a number of researchers in the positive organizational scholarship have focused on virtuousness effects of ethical behavior and its role that plays in organizational performance areas such as innovation, turnover, quality and profitability etc. (Barclay, Markel and Yugo, 2012: 331).

In a fiercely competitive global setting, achieving organizational effectiveness and in order to cope effectively with these conditions individuals and organizations must adhere to ethical behaviors; they must also act virtuously and foster virtuousness. For this reason and positive outcomes, virtuousness has gained importance in organizational behavior researches. Several researchers documented that virtuousness have positive effects on both organizations and employees. Organizational perspective, virtuousness produce positive energy that leads to enhance performance, employee innovation, expanded social capital development, increases prosocial behavior and the development of resiliency, enhance corporate image. However, virtuousness leads to employee's exhibit organizational citizenship behaviors much more. On the other hand, researchers suggest that virtuousness involves some favorable outcomes such as commitment, satis faction, motivation, positive emotions, psychical an d psychological health (Cameron, Dutton and Quinn, 2003: 58-63; Cameron, 2008: 17; Sarlak, 2011: 216-218).

\subsection{Work Values}

Kluckhohn (1951) proposed that values are unique explicit or implicit philosophy held by an individual or group regarding matters they have influence over and it refers to a concept of what is good, right and worthy. Work values are a part of the individual values system and are an extension of the implications in "values". Work values are defined as an intrinsic driving force that pushes an individual to move towards their life goals and it also guides the direction and motivation of their behavior (Lee and Yen, 2013: 804). Work values refer to what an individual wants out of their work and 'work-related reinforcement preferences or tendencies to value specific types of incentives in the work environment (Chu and $\mathrm{Chu}, 2013: 1151$ ). In addition, work values are also characterized as how employees values their interpersonal interactions and social contributions in the work context, the influence of their work, and the influences on their own reputation or authority in organizations. Concordantly, in organizational settings, work values determine the fit of an employee with his/her organization, it reflect pers onal needs or the environmental preferences of individuals and they also guide the work behavior of individuals, dictate their goals and the likelihood of his/her intention to leave the organization (Liao et al., 2012: 5300; Chen and Kao, 2012: 151). Accordingly, it is possible to express that work values shape employees' perception of preferences in the workplace, exerting a direct influence on employee attitudes and behavior (Gursoy, Chi and Karadag, 2013: 41). 
For this reason, work values have received considerable attention for many decades due to its importance in determining employee attitudes and behaviors. In literature, several studies reported that values are likely to have significant influence over a variety of attitudes and behaviors in organizations. Researchers suggest that work values have been related to work involvement, work motivation, job satisfaction, organizational commitment, job burnout, job performance, career choice and showing initiative in one's work. However, work values have an influence on hiring and retention rates in organizations and can affect the willingness of individuals to work diligently. Work values also affect organizational citizenship behaviors and ethical behaviors of employees. (White, 2006: 703; Gursoy, Maier and Chi, 2008: 450; Leuty and Hansen, 2011: 388; Liao et al., 2012: 5301; Wang, Hyde and Hsieh, 2010: 873; Liang, 2012: 255). Therefore, work values would form a general pattern of behavior of an individual and these were a projection of general values from the domain of work. From this perspective, work values can be seen as the goals people would strive hard to attain in their work and as a representation of work ethics (Teng, 2010: 13). Finally, work values as endurable beliefs and standards which judge the worth of what is done through work, justify the work experience and express one's work behavior as particularly ethical behaviors. In other words, it is an enduring perspective that guides individuals to evaluate what is fundamentally right or wrong in the work environment (Ho, 2006: 22; Liang, 2012: 252).

\subsection{Ethical Behavior}

The word 'ethic' comes from the Greek word ethos, which means "the character, custom or a set of moral behavior that is accepted extensively." Ethics also can be defined as the conception of what is right and fair conduct or behavior. In other words, ethics is the concept ofmorals; one's ability to choose between right and wrong, good and bad, acceptable and unacceptable norms (Jalil, Azam and Rahman, 2010: 146). Ethics is a system of moral principles where "morality" refers to principles of good behavior. It can thus be stated that ethical behavior in a business sense refers to business principles that will lead to acceptable good business behavior in dynamic environment (Zyl and Lazenby, 2002: 112). Ethical behavior can generally be defined as a behavior that is considered right or wrong, and therefore directs what people should and should not do in work life. However, ethical behavior is guided by "rules, standards, codes, or principles which provide guidelines for morally right behavior and truthfulness in organizations. In today's businesses ethical behavior can be described as "fair and honest actions" that enable the company to obtain customer satisfaction and positive corporate image and develop a long term relationship with its customers (McCain, Tsai and Bellino, 2010: 994). Therefore, in a fiercely competitive global era, achieving organizational effectiveness and organizational survival is based on employee's ethical attitudes and behaviors. For this reason, ethicalbehavior in organizations has gained importance. Today, it becomes an important for organizations to better understand the factors that influence employee's ethical behavior and the factors that are affected by ethical behaviors.

Ethics has been one of the principal issues confronting businesses for many years. Businesses are responsible for maximizing long-term value and organizational performance, because of that they enforce and adhere to certain ethical standards and ethical behaviors. Ethical behaviors have been the subject of controversy and debate for many years among researchers and practitioners. In accordance with these debates, scholars and practitioners are wondering what has to be done to assure ethical behaviors in the business environment (Aydemir and Egilmez, 2010: 72). Accordingly, it is critical for organizations to establish an ethical culture in which employees are encouraged to behave ethically. Based on the importance of ethical behaviors in organizations, researches have investigated the antecedents of ethical behaviors. These antecedents have been classified as either individual or situational. Individual antecedents include personality characteristics whereas a situational characteristic refers to policies, systems and procedures of organizations.

Ethical behaviors have become one of the most significant issues facing today's corporate world. Particularly, in some industries ethical behaviors become more important like service industry. Hotel establishments are basic components in this industry. However, in hotel establishments, ethical behaviors much more determinant factor because it reflects the aggregation of individual employees 'characters. For this reason, hotel establishments emphasizes that the importance of promoting ethical behavior and the antecedents of these behaviors (McCain, Tsai and Bellino, 2010: 993). Therefore managing ethical behavior as a critical social problem for organizations and it is a complex problem 
which contributes to employee's decision to behave ethically and unethically (Stead et all., 1990: 234). In this context, current researches focus on individual and organizational factors for explanation of ethical behaviors. When we examine individual factors, it can be seen that some of them classified as a personality characteristics and other are grouped according to managerial attitudes and managerial systems in organizations.

\subsection{The Relationships among Self-Esteem, Virtuousness, Work Values and Ethical Behaviors}

In literature, self-esteem and virtuousness are classified personal characteristics refer to an individual's values, attitudes, moral character, and ethical sensitivity. Individual factors influence of a company are extremely important for running business an ethically because these factors represents individuals characters and have a great impact on their behaviors. Organizational factors refer to a company's ethical climate, which relates to employees' perception of a company's "current practices, procedures, norms, and values within an ethical context that provides cues about acceptable behaviors. Therefore, employees' ethical behavior is influenced by whether or not the company's policies, procedures, and decision making are fair and just. In other words, an employee's moral and ethical attitude are shaped by their perception of the organization fairness and work values (McCain, Tsai and Bellino, 2010: 994). In this context, it is possible to assess that individual and organizational factors have plays a critical role in ethical behaviors. Ethical behaviors can be seen an important as set in organizations, because it guide employees and organization in the right direction. However, ethical behaviors increases the reputation of the business organization, ensures its continuous development and helps to achieve customer satisfaction and increases employees job satisfaction, motivation and organizational commitment. The possible contents of ethical behaviors are wide and varied (Jalil, Azam and Rahman, 2010: 146). In other words, researches have been explored outcomes of ethical behaviors such as job satisfaction, organizational commitment, turnover intention and organizational citizenship behaviors. Though a variety of antecedents to ethical behavior have been explored, the outcomes of employee ethical behavior in organizations have rarely been examined. At the same time, there is little consistency in the literature on exactly what constitutes ethical behavior. (Baker, Hunt and Andrews, 2006: 850). Prior literature suggests that some individual and organizational factors affect ethical behaviors. There are some researches (Zyl and Lazenby, 2002; Baker, Hunt and Andrews, 2006; McDevitt, Giapponi and Tromley, 2007; Murphy, 2007; McCain, Tsai and Bellino, 2010; Gangwani, 2012) that examine the relationships between individual factors, organizational factors and ethical behaviors. But, there are limited researches that have discussed the relationships between them. In this study, we have discussed some of these factors. Within the scope of individual factors, we take self-esteem and virtuousness which are expected to affect ethical behaviors and from the scope of organizational factors, we have taken work values. Thus, this study aims to investigate the relationships among self-esteem, virtuousness, work values and ethical behaviors. In order to test these relationships, research modeland hypothesis those shown below are developed.

\section{Individual Factors}



Fig. 1. Research Model

H1: There is a statistically significant relationship between self-esteem and ethical behaviors.

$\mathrm{H} 2$ : There is a statistically significant relationship between virtuousness and ethical behaviors. 
H3: There is a statistically significant relationship between work values and ethical behaviors.

\section{Research Methodology}

\subsection{Sample and Procedures}

This study encompassed employees from hotelestablishments in Turkey. The sample used for the study consists of approximately 250 staff, who serves in various positions in 10 hotels which are determined via convenient sampling method. From the 250 questionnaires variabile been sent, 180 (\%72) have returned and $174(\% 70)$ have been accepted as valid and included in the evaluations. Questionnaire survey method is used for data collection. Questionnaire form contains four different measurement related to our research variabiles.

\subsection{Meas urement}

Measures used in the questionnaire are adapted from previous studies in literature. The variables used in the self-esteem measure; is taken from Tinakon and Nahathai (2012) study, the variables virtuousness measure is taken from Thun and Kelloway (2011) study. The variables work values is taken from Furnham et al. (2005) study and ethical behaviors measure are taken from Hill and Swanson (1985); Zyl and Lazenby (2002) studies. For answers to the statements of survey, a Likerttype metric, that is, expressions with five intervals has been used. Anchored such;" 1 - strongly disagree, 2- disagree, 3- neither agree or nor disagree, 4- agree, 5-strongly agree". There are also 7 demographic questions in the questionnaire. As a result of the conducted pilot study, it's been observed that the items in the factor analysis, where $(n=30)$ has been applied, displayed a proper distribution, in accordance with the theoretical characteristics.

\subsection{Statis tical Methods}

The data obtained from the study, have been evaluated via SPSS for Windows 20.0 program. Factor analysis is used to test the variables related to self-esteem, virtuousness, work values and ethical behaviors dimensions. After the Factor Analysis performed in order to test the validity of measures, the internal consistency coefficients (Cronbach's Alpha) were calculated separately for each measure. The correlation analysis method was used to determine the presence of interdependency among variables and to test the research hypotheses; and for the explanation of relationships among variables, which are determined by means of correlation analysis, the multi-dimensional regression analysis was utilized.

\section{Results}

\subsection{Demographical Findings}

$71 \%$ of employees, who have participated in the research, are male and $29 \%$ are female. $38 \%$ of the employees are between the ages 26-30, approximately $30 \%$ of them are between the ages of $31-35,7 \%$ of them are older than 36 and $25 \%$ of them younger than $25.45 \%$ of employees have education of a high school, $35 \%$ have graduated from vocational school. $19 \%$ of employees have bachelor's degree and $6 \%$ of the employees have master's level education. Approximately $64 \%$ of employees are working in $\mathrm{F} \& \mathrm{~B}$ department, $13 \%$ of them are working in front office department and $13 \%$ of them are working in housekeeping department. $29 \%$ of employees have been working less than one year, $46 \%$ of them have been working between $1-3$ years, $22 \%$ of them have been working between $4-6$ years and $3 \%$ of the employees have been working more than 6 years in the this firm.

\subsection{Factor and Reliability Analysis}

In the study, the structural validity and reliability levels of measures have been tested. First, data of the variables related to virtuousness have been put into factor analysis and the varimax rotation has been obtained. In the principal component analysis, the Kaiser-Meyer-Olkin test result (KMO value, 0.848) 
and the result of Bartlett test $(903.257 ; \mathrm{p}<0.01)$ are significant. As a result of the varimax rotation of the data related to virtuousness variables, removing the items with factor loadings under 0.50 from the analys is, two factor solutions has been obtained. Emerged factors, explain $63.583 \%$ of the totalvariance. It can be seen that the remaining 10 items are grouped under the relevant factors as per theoretical structure. It can be said that the scale which are used can measure a single structure that complies with the theory and has structural validity. The findings on the resultant factors, factor loadings, explained variances, and internal consistency coefficients which are calculated for each factor (measure) are summarized in Table 1.

Table 1. Rotated Factor Loadings with Calculated Virtuousness Measures

\begin{tabular}{|c|c|}
\hline \multicolumn{2}{|c|}{ Factor 1: Humanity\& Te mper ance (explained variance $=52.157 \% ;$ Cronbach's Alpha $=0.87$ ) } \\
\hline Exercises appropriate levels of caution & 0.846 \\
\hline 2. Follows through no matter what & 0.828 \\
\hline 3. Level-headed even when things are difficult or tense & 0.761 \\
\hline 4. Demonstrates sincere appreciation for work that is done well & 0.729 \\
\hline 5. Is caring and/or compassionate & 0.619 \\
\hline 6. Cares immensely for me & 0.547 \\
\hline \multicolumn{2}{|c|}{ Factor 2: Wisdom (explained variance $=11.426 \% ;$ Cronbach's Alpha $=0.79$ ) } \\
\hline 7. Enjoys trying new things & 0.791 \\
\hline 8. Seeks unique ways to do things or solve problems & 0.788 \\
\hline 9. Willingly considers viewpoints other than his/her own & 0.699 \\
\hline 10. Committed to life-long learning & 0.662 \\
\hline
\end{tabular}

The data of the variables related to work values have been put into factor analysis and the varimax rotation has been obtained. In the principal component analysis, the Kaiser-Meyer-Olkin test result (KMO value, 0.884) and the result of Bartlett test $(4420,497 ; \mathrm{p}<0.01)$ are significant. As a result of the varimax rotation of the data related to work values variables, removing the items with factor loadings under 0.50 from the analys is, four factor solutions has been obtained. Emerged factors, explain $69.680 \%$ of the total variance. It can be seen that the remaining 27 items are grouped under the relevant factors as per theoretical structure. It can be said that the scales which are used can measure a single structure that complies with the theory and have structural validity. The findings on the resultant factors, factor loadings, explained variances, and internal consistency coefficients which are calculated for each factor (measure) are summarized in Table 2.

Table 2. Rotated Factor Loadings with Calculated Work Values Measures

\begin{tabular}{lc}
\hline Factor 1: Autonomy and Use of Skills (explained variance=44.716\%; Cronbach's Alpha=0.93) \\
1. To do work which is personally very interesting to you & 0.898 \\
2. Autonomy and personal freedom & 0.845 \\
3. Chance to use your skills and abilities & 0.844 \\
4. Respectful and convenient job & 0.742 \\
5. Support for improving abilities & 0.719 \\
6. Provides behave innovative & 0.661
\end{tabular}

Factor 2: Work Relationships (explained variance=10.060\%; Cronbach's Alpha=0.93)

7. Positive relationships with work colleagues and subordinates

8. Harmony among all groups in your organization $\quad 0.859$

9. Being trusted by all people you work with 0.816

10. Positive relationships with work colleagues

$0.816 \quad 0.701$

11. Clarity of your work goals and targets $\quad 0.680$

$\begin{array}{ll}\text { 12. A fair and considerate boss } & 0.674\end{array}$

13. Sense that you are valued as colleague or worker $\quad 0.627$

14. Feedback (regular) concerning the results of your work $\quad 0.618$ 
Factor 3: Financial and Working Conditions (explained variance= 9.013\%; Cronbach's Alpha= 0.86)

16. A high competitive salary by performance related systems or rapid promotion 0.800

17. Benefits (vacation, sick leave, pensions, insurance)

18. Job security

19. Human resource backup

20. People being equitably paid for performance compared to others

21. Not being overworked to exhaustion

22. Being provided with all necessary and up-to-date equipment

Factor 4 . Influence and Advancement (explained variance 0.512

23. To have a job others recognize as very high status

24. Personal success at work

0.849

25. Opportunity for personal growth and development

26. Being respected for your skills and input

27. Influence within the organization as a whole

0.538

The data of the variables related to self-esteemhave been put into factor analysis. In the principal component analysis, the Kaiser-Meyer-Olkin test result (KMO value, 0.722) and the result of Bartlett test $(114,720 ; \mathrm{p}<0.01)$ are significant. As a result of the factor analysis, one factor solutions has been obtained. Emerged factor, explain $52.289 \%$ of the total variance. It can be seen that the remaining 4 items are grouped under the relevant factor as per theoretical structure. It can be said that the scale which is used can measure a single structure that complies with the theory and have structural validity. The findings on the resultant factor analysis are summarized in Table 3.

Table 3. Factor Loadings with Calculated Self-Esteem Measures

Factor 1: Self-Esteem (explained variance= 52.289\%; Cronbach's Alpha=0.69)

1. On the whole, I am satisfied with myself.

0.800

2. I am able to do things as well as most other people. $\quad 0.737$

3. I wish I could have more respect for myself.

4. I take a positive attitude toward myself.

0.604

The data of the variables related to ethical behavior have been put into factor analysis. In the principal component analysis, the Kaiser-Meyer-Olkin test result (KMO value, 0.853) and the result of Bartlett test $(617,882 ; \mathrm{p}<0.01)$ are significant. As a result of the factor analys is, one factor solutions has been obtained. Emerged factor, explain $52.693 \%$ of the total variance. It can be seen that the remaining 8 items are grouped under the relevant factor as per theoretical structure. It can be said that the scale which is used can measure a single structure that complies with the theory and have structural validity. The findings on the resultant factor analys is are summarized in Table 4.

Table 4. Factor Loadings with Calculated Ethical Behavior Measures

Factor 1: Ethical Behavior (explained variance $=52.693 \%$; Cronbach's Alpha $=0.86$ )

1. Verbalizes judgments on rightness or wrongness of certain behaviors $\quad 0.868$

2. Understands and shows an effort to understand 0.818

3. Is willing to help someone in need whether good friend or not

4. Verbalizes loyalty to a group or institution $\quad 0.753$

$\begin{array}{ll}\text { 5. Will admit a mistake } & 0.695\end{array}$

6. Will refuse to go along with others in wrongdoing $\quad 0.657$

7. Shows a genuine concern for the welfare of fellow humans 0.593

8. Treats others with respect 


\subsection{Findings on the Research Hypotheses}

Obtained through correlation analysis which is performed to test the existence of relationships, the findings in the research hypothesis denote the relationships among the dimensions which are summarized in Table 5.

\section{Table 5. The Correlation among Virtuousness, Self-Esteem, Work Values and Ethical Behaviors}

\begin{tabular}{lllcll} 
& 1 & 2 & 3 & 4 & Means \\
5. Virtuousness & 1 & & & & 3.97 \\
6. Work Values & $.559^{* *}$ & 1 & & & 3.45 \\
7. Ethical Behaviors & $.392^{* *}$ & $.208^{* *}$ & 1 & & 4.27 \\
8. Self-Esteem & $.464^{* *}$ & $.172^{*}$ & $.295^{* *}$ & & 1 \\
\hline
\end{tabular}

${ }^{* *} \mathrm{p}<0.01,{ }^{*} \mathrm{p}<0.05$

In correlation analysis findings, a significant relationship $(r=392, p<0.01)$ is observed between the virtuousness and ethical behaviors. There is a significant relationship $(\mathrm{r}=208, \mathrm{p}<0.01)$ between work values and ethical behaviors. There is a significant relationship between self-esteem $(\mathrm{r}=295, \mathrm{p}<0.01)$ and ethical behaviors. Accordingly, the $\mathrm{H} 1, \mathrm{H} 2$ and $\mathrm{H} 3$ hypothes is are accepted. The findings obtained as a result of the correlation analysis performed on testing the existence of relationships denoted in the research hypothesis, and the findings obtained as a result of regression analysis performed for explanation of relationships between the dimensions are summarized in Table 6 and 7.

Table 6. Effects of Virtuousness and Self-Esteem on Ethical Behaviors

\begin{tabular}{lcccc}
\hline & $\mathrm{R}^{2}$ & $\mathrm{~F}$ & $\beta$ & $\mathrm{p}$ \\
& .217 & 15.734 & & .000 \\
Humanity \& Temperance & & & .445 & .000 \\
Wisdom & & -.103 & .265 \\
Self-Esteem & & .159 & .040 \\
$* * \mathrm{p}<0.01, * \mathrm{p}<0.05$ & & &
\end{tabular}

Table 6 indicates the results of the regression analysis, which explain effects of the virtuousness dimensions and self-esteem on ethical behaviors. Model summary, Table 6 shows how much virtuousness and self-esteem variables can explain ethical behaviors. $21.7 \%$ ethical behaviors of the variance are explained by one of the dimension of virtuousness and self-esteem. The regression model, explaining the impact of virtuousness and self-esteem on ethical behaviors, is valid (with $\mathrm{F}=15.734$; $\mathrm{p}<0.01$ ). Positive beta values show that the increase in independent variables leads to an increase in ethical behaviors, or a decrease in independent variables results in a decrease in ethical behaviors. Accordingly; it can be said that humanity and temperance dimensions of virtuousness and self-esteem affect the ethical behaviors positively. In other words, if employees have a personality trait which can be characterize virtuousness and self-esteem, they will exhibit ethical behaviors much more than others. According to beta values; the ethical behaviors are affected mostly from humanity \& temperance dimension of virtuousness than self-esteem.

Table 7. Effects of Work Values on Ethical Behaviors

\begin{tabular}{|c|c|c|c|c|c|}
\hline & $\begin{array}{l}\mathrm{R}^{2} \\
.158\end{array}$ & 7.939 & & $\beta$ & .000 \\
\hline Influence and Advancement & & & & .432 & \\
\hline Work Relationships & & & .197 & & .048 \\
\hline Financial and Working Conditions & & & -.292 & & .005 \\
\hline Autonomy and Use of Skills & & & & -.024 & \\
\hline
\end{tabular}


Table 7 indicates the results of the regression analysis, which explain effects of the work values dimensions on ethical behaviors. Model summary, Table 7 shows how much work values variables can explain ethical behaviors. $15.8 \%$ ethical behaviors of the variance are explained by three dimensions of work values. The regression model, explaining the impact of work values on ethical behaviors, is valid (with $\mathrm{F}=7.939 ; \mathrm{p}<0.01$ ). Accordingly; it can be said that influence and advancement, work relationships affect the ethical behaviors positively. However, financial and working conditions affect ethical behaviors negatively. In other words, if employees perceive influence \& advancement and positive work relationships in organizations, it is expected them exhibit ethical behaviors in working area. According to beta values; ethical behaviors are affected mostly from influence and advancement dimension of work values.

\section{Conclusion}

Ethical behaviors are one of the critical and important factors for organizations to achieve sustainable competitive advantage in today's dynamic working conditions. These conditions require organizations to be differing fromtheir rivals and to do best towards their customers. Therefore, if organizations desire to struggle rivals and acquire customer satisfaction, they need to give an importance to their employees more than ever. In other words, organizations try to attract qualified and positive personality traits employees and keep employing them in positive working conditions. Because personality characters', qualifications and working values in organizations are thought to be an important factors on an employee's attitudes and behaviors. However, it is possible that employees who have positive personality traits and who perceive positive work values can be demonstrate positive attitudes towards colleagues and their organization. On the other hand, a negatively perceived work values and negative traits of employees are expected to exhibiting unethical behaviors in organization. Thus, self-esteem and virtuousness which are characterized both as a personality trait and individual factors are considered as one of the precursors which are effective on employees' exhibiting ethical behavior. In addition to this, work values are examined as one of the determinant organizational factors which are possible to effect employee's ethical behavior. In literature, ethical behaviors antecedents are categorized as an individual and organizational perspective. Concordantly, it is possible to see lots of studies dealing with many individual and organizational variables such as personality traits, locus of control, ethical clima te, organizational policies, procedures, fairness etc. Among all these studies, there is no study that examines specific individual traits like self-esteem and virtuousness; also there aren't any studies which were taken these variables together. In this context, this study aims to investigate the impact of individual and organizational factors on ethical behaviors' at the same time. Therefore, it is believed that this study will contribute to and fill the gap in the literature.

As a result of the research carried out to determine the effect of self-esteem, virtuousness and work values on ethical behaviors, it has been found out that there is a significant relationship among them. In other words, there is a significant relationship between self-esteem and ethical behaviors, virtuousness and ethical behavior and also work values and ethical behaviors. Moreover H1, H2 and H3 hypothesis have been accepted. Besides, when the impact of virtuousness and self-esteem effects on ethical behaviors are examined, it has been found out that humanity and temperance dimension of virtuousness and self-esteem have a positive effect on ethical behaviors, but however wisdomhas no effect on ethical behaviors. Because, humanity and temperance dimension of virtuousness refers to moral sense than wisdom. Wisdom is related with creativity, curiosity, open-mindedness; humanity and temperance are relevant with kindness, self-regulation and strength aspects of character. Accordingly, it can be said that ethical behaviors can be affected much more humanity and temperance. In the other perspective, when the research findings are analysed, it can be seen that virtuousness has an effect on ethical behaviors most than self-esteem. In other words, virtuousness represents one's morality, whereas self-esteem refers to one's thought of him or herself, so it is expected that virtuousness related with ethical behaviours much more than self-esteem. In addition to this, other finding shows that work values effect ethical behaviors. But when we examine the dimensions of work values, it has been found out that working relations and influence \& advancement affect ethical behaviour's positively as financial and working conditions negatively. However, influence \& advancement affect ethical behaviour's much 
more than working relations. In this regard, it can be said that ethical behaviors affected influence and advancement values most. That is, when employees perceive that organization gives them personal growth and development opportunity and provides them high status in time, it is expected ethical behaviour's from employees. Because if employees perceive work values supportive and satis fied with these values they will exhibit positive behaviors like ethical behaviors. The other research finding shows that financial and working conditions affect ethical behaviors negatively, in other words, in the scope of business there is a negative conditions view of compensation and reward politics and working conditions such as job security, benefits etc. So these conditions trigger employees behave unethical.

The findings of the research can be regarded as appropriate for the theoretical basis. Because, a warm and supportive working values perceived by the employee are expected to influence the attitudes and behaviours. Besides, if employees have positive characteristics such as self-esteem and virtuousness, then these are thought to be effective in employees' positive or negative behaviours. In this context, it can be said that perceiving a warm relationships, supportive politicise and procedures and positive working conditions will lead employees to exhibit ethical behavior and avoid from unethical behavior. In this regard, individual factors such as self-esteem and virtuousness and work values which refer to organizational component are expected to show employees either positively or negatively. The study can be expanded by adding other variables which are classified in individual or organizational perspective. For example, it is possible to add a big five personality traits, self-efficacy and optimism as an individual factor thus the research model will be expanded. However, in addition to these individual variables it can be added some organizational factors such as organizational climate, management styles or human res ource policies so considerably an expanded model can be presented.

\section{References}

1. Aydemir, M. and Egilmez, O.: An Important Antecedent of Ethical/Unethical Behavior: Religiosity, Eurasian Journal of Business and Economics, Vol. 3, No. 6 (2010) 71-84.

2. Azmi, R. A.: Business Ethics as Competitive Advantage for Companies in the Globalization Era, Working Paper, http://ssrn.com/abstract=1010073 (2006).

3. Baker, T. L., Hunt, T. G. and Andrews, M. C.: Promoting Ethical Behavior and Organizational Citizenship Behaviors: The Influence of Corporate Ethical Values, Journal of Business Research 59 (2006) 849-857.

4. Barclay, L.A., Markel, K.S. and Yugo, J.E.: Virtue Theory and Organizations: Considering Persons with Disabilities, Journal of Managerial Psychology, Vol. 27, No. 4 (2012) 330-346.

5. Barsky, A.E.: Ethics and Values in Social Work: An Integrated Approach for a Comprehensive Curriculum, NY: Oxford University Press, UK. (2010).

6. Baumeister, R. F., Campbell, J. D., Krueger, J. I. and Vohs, K. D.: Does High Self-Esteem Cause Better Performance, Interpersonal Success, Happiness, or Healthier Lifestyles, Psychological Science in the Public Interest, Vol. 4, No. 1 (2003) 1-44.

7. Cameron, K., Dutton, J. and Quinn, R.: Positive Organizational Scholarship: Foundations of a New Discipline, Berrett-Koehler Publishers, San Francisco (2003).

8. Cameron, K.S.: Paradox in Positive Organizational Change, Journal of Applied Behavioral Science, Vol. 44, No: 7 (2008) 7-24.

9. Caza, A., Barker B. A. and Cameron, K. S.: Ethics and Ethos: The Buffering and Amplifying Effects of Ethical Behavior and Virtuousness, Journal of Business Ethics 52 (2004)169-178.

10. Chen, C.V. and Kao, R.H.: Work Values and Service-Oriented Organizational Citizenship Behaviors: The Mediation of Psychological Contract and Professional Commitment: A Case of Students in Taiwan Police College, Soc Indic Res, 107 (2012) 149-169.

11. Chu, A.Z. and Chu, R.J.: Service Willingness and Senior Tourists: Knowledge About Aging, Attitudes Toward the Elderly, and Work Values, the Service Industries Journal, Vol. 33, No. 12 (2013) 1148-1164.

12. Ferris, D. L., Brown, H. L. D. J., Pang, F. X. J. and Keeping, L. M.: Self-Esteem and Job Performance: The Moderating Role of Self-Esteem Contingencies, Personnel Psychology, Vol. 63 (2010) 561-593. 
13. Furnham, A., Petrides, K.V., Tsaousis, I., Pappas, K. and Garrod, D.: A Cross -Cultural Investigation into the Relationships between Personality Traits and Work Values, The Journal of Psychology, Vol. 139 (2005) 5-32.

14. Gangwani, S.: The Impact of Demographic Variables on Ethical Behavior of Employees at their Workplace, BAUDDHIK, Vol. 3, No. 1 (2012) 44-53.

15. Gursoy, D., Maier, T.A. and Chi, C.G.: Generational Differences: An Examination of Work Values and Generational Gaps in The Hospitality Workforce, International Journal of Hospitality Management, 27 (2008) 448-458.

16. Gursoy, D., Chi, C.G. and Karadag, E.: Generational Differences in Work Values and Attitudes among Frontline and Service Contact Employees, International Journal of Hospitality Management, 32 (2013) 40-48.

17. Hackett, R.D. and Wang, G.: Virtues and Leadership: An Integrating Conceptual Framework Founded in Aristotelian and Confucian Perspectives on Virtues, Management Decision, Vol. 50, No. 5 (2012) 868 -899.

18. Hill, G. and Swanson, H. L.: Construct validity and reliability of the ethical behavior rating scale, Educational and Psychological Measurement, 45 (1985) 285-292.

19. Ho. C.: A Study of the Relationship between Work Values, Job Involvement and Organizational Commitment among Taiwanese Nurses, Queensland University of Technology, Doctor of Health, Australia (2006).

20. Jalil, M. A., Azam, F. and Rahman, M. K.: Implementation Mechanism of Ethics in Business Organizations, International Business Research Vol. 3, No. 4 (2010) 1-11.

21. Kuster, F., Orth, U. and Meier, L. L.: High Self-Esteem Prospectively Predicts Better Work Conditions and Outcomes, Social Psychological and Personality Science 00(0) (2013) 1-8.

22. Lee, H. and Yen, K.: A Study of the Relationship between Work Values and Career Orientation of Employed in the High Technology Industry, Qual Quant, 47 (2013) 803-810.

23. Leuty, M.E. and Hansen, J.C.: Evidence of Construct Validity for Work Values, Journal of Vocational Behavior, 79 (2011) 379-390.

24. Liang, Y:: The Relationships among Work Values, Burnout, and Organizational Citizenship Behaviors: A Study from Hotel Front-Line Service Employees in Taiwan, International Journal of Contemporary Hospitality Management, Vol. 24, No. 2 (2012) 251-268.

25. Liao, C., Lu, C., Huang, C. and Chiang, T.: Work Values, Work Attitude and Job Performance of Green Energy Industry Employees in Taiwan, African Journal of Business Management Vol. 6, No. 15 (2012) 5299-5318.

26. Mann, M., Hosman, C.M., Schaalma, H.P. and Vries, N.K.: Self-Esteem in a Broad-Spectrum Approach for Mental Health Promotion, Health Education Research, Vol. 19, No.4 2004 357-372.

27. Ma, Li.: Work-Based Self-Esteem: Conceptual, Theoretical and Scale Development and Model Testing, Washington University, Doctor Of Philosophy. (2008).

28. McCain, S. L. C., Tsai, H. and Bellino, N.: Organizational Justice, Employees' Ethical Behavior, and Job Satisfaction in the Casino Industry, International Journal of Contemporary Hospitality Management, Vol. 22, No. 7 (2010) 992-1009.

29. McDevitt, R., Giapponi, C. and Tromley, C.: A Model of Ethical Decision Making: The Integration of Process and Content, Journal of Business Ethics, Vol. 73 (2007) 219-229.

30. Mruk, C. J.: Self-Esteem Research, Theory and Practice, Toward a Positive Psychology of SelfEsteem, Springer Publishing Group, New York (2006).

31. Pierce, J. L. and Gardner, D.G.: Self-Esteem within the Work and Organizational Context: A Review of the Organization-Based Self-Esteem Literature, Journal of Management, Vol. 30, No. 5 (2004) 591-622.

32. Rego, A., Cunha, M. P. and Clegg, S. T.: The Virtues of Leadership, Oxford University Press, UK (2012).

33. Rezaee, Z.: Corporate Governance and Ethics, John Wiley \& Sons. Inc, USA. Trevino and Nelson, Managing Business Ethics, John Wiley \& Sons.Inc, 5th Edition, USA (2008).

34. Sánchez, R. M, and Medina, C.: Improving Ethical Decision-Making in Organizations through Ethical Competencies, WP BOM Working Paper Series (2012).

35. Sarlak, M.A.: The New Faces of Organizations in the 21st Century, NAISIT Publishers, Canada. (2011). 
36. Selvarajan, T. T. and Sardessai, R.: Appraisal of Ethical Performance: A Theoretical Model, The Journal of Applied Business Research, Vol. 26, No. 3 (2010) 1-8.

37. Stead, W. E., Worrell, W. E. and Stead, J. G.: An Integrative Model for Understanding and Managing Ethical Behavior in Business Organizations, Journal of Business Ethics, 9 (1990) 233-242.

38. Teng, L.C.: Relationship between Work Values and Job Involvement: A Study among Manufacturing Operators in the Packaging Industries in Penang, Universiti Sains Malaysia (2010).

39. Thun, B. and Kelloway, E. K.: Virtuous Leaders: Assessing Character Strengths in the Workplace, Canadian Journal of Administrative Sciences, 28 (2011) 270-283.

40. Tinakon, W. and Nahathai, W .: A Comparison of Reliability and Construct Validity Between The Original and Revised Versions of the Rosenberg Self-Esteem Scale, Korean Neuropsychiatric Association (2012) 54-58.

41. Treadway, D. C.: Political Will in Organizations, Ferris, G. R and Treadway, D. C. Politics in Organizations, Taylor \& Francis Group, New York (2012).

42. Trevino, L. K. and Nelson, K. A.: Managing Business Ethics, Library of Congress Cataloging, 5th Edition, USA (2011).

43. Wang, C. Y., Chen, M. H., Hyde, B. and Hsieh, L.: Chinese Employees' Work Values and Turnover Intentions in Multinational Companies: The Mediation Effect of Pay Satisfaction, Social Behavior and Personality, Vol. 38, No.7 (2010) 871-894.

44. White, C.: Towards an Understanding of the Relationship between Work Values and Cultural Orientations, Hospitality Management, 25 (2006) 699-715.

45. Zaal, R.O.S.: Reinforcing Ethical Behavior through Organizational Architecture, McCharty, K. J, Fiolet, M, and Dolfsma, W. The Nature of the New Firm, Edward Elgar Publishing, UK (2011).

46. Zyl, E. and Lazenby, K.: The Relation between Ethical Behavior And Work Stress Amongst A Group Of Managers Working in Affirmative Action Positions, Journal of Business Ethics, 40 (2002) 111-119. 